\title{
On the determination of characteristics of the interior ocean dynamics from radar signatures of internal solitary waves
}

\author{
P. Brandt ${ }^{1}$, R. Romeiser, and A. Rubino \\ Institut für Meereskunde, Universitat Hamburg, Hamburg, Germany
}

\begin{abstract}
In this paper we discuss two different methods of inferring characteristics of the interior ocean dynamics from radar signatures of internal solitary waves visible on synthetic aperture radar (SAR) images. The first one consists in the recognition and the interpretation of sea surface patterns of internal solitary waves; the second one consists in the analysis of the modulation depth of the normalized radar backscattering cross section (NRCS) associated with internal solitary waves. For this purpose we consider a data set composed of SAR and in situ measurements carried out from 1991 to 1997 in the region of the Strait of Messina. The recognition and the interpretation of sea surface patterns of internal solitary waves in the Strait of Messina can be used to study characteristics of the density distribution in the area: The internal wave field varies with seasonal variations in the vertical density stratification and with remotely induced variations, i.e., variations induced by the larger-scale circulation, in the horizontal density distribution. In order to inquire into the possibility of inferring parameters of the interior ocean dynamics by analyzing the modulation of the NRCS associated with internal solitary waves, several numerical simulations are carried out using a radar imaging model. These simulations are performed by assuming different wind conditions and internal wave parameters. It is shown that an accurate knowledge of wind conditions is crucial for deriving internal wave parameters and hence parameters of the interior ocean dynamics from the modulation of measured NRCS associated with internal solitary waves.
\end{abstract}

\section{Introduction}

Tidally induced internal waves are generated, in a stratified ocean, by the interaction of a tidal flow with topographic features like, for example, strait sills, oceanic ridges, or continental shelf breaks. With the advent of remote sensing, the existence of tidally induced internal waves, often ranked in trains of internal solitary waves, was revealed in all of the world ocean. The acknowledgment of the ubiquity of tidally induced internal waves, achieved through satellite observations, suggests that these oceanic features exert a significant contribution to the dissipation of the rotational energy of the Earth-Moon system and to the mixing of different water masses in the ocean [Apel et al., 1995]. Among the different remote sensing techniques, radar remote sensing has proved to be a powerful tool for the study of oceanic internal waves [Apel et al., 1975; Alpers and Salusti, 1983; Watson and Robinson, 1990; Richez, 1994; Alpers et al., 1996]. These oceanic features become visible on radar images because they are associated with variable surface currents that modulate the surface roughness patterns. Note that in recent years, the role of surface films in the modulation of the sea surface roughness,

${ }^{\bar{N}}$ Now at Institut für Meereskunde, Universitat Kiel, Kiel, Germany. which takes place mainly via wave-current interaction, has been the topic of a large number of investigations [see, e.g., da Silva et al., 1998; Ermakov et al., 1998, and references therein]. Usually, the study of radar signatures associated with internal solitary waves is based on two different ways of analyzing the data: The first one consists in the recognition and the interpretation of their sea surface patterns [Apel and Gonzales, 1983; Artale et al.,1990; Brandt et al., 1997, 1999; Rodenas and Garello, 1997]; the second one consists in the analysis of the modulation of the normalized radar backscattering cross section (NRCS) associated with internal solitary waves [Alpers, 1985; Apel et al., 1988]. Different parameters which can be obtained from such analyses like, for example, occurrence of sea surface patterns of internal solitary waves, location of the internal wave fronts as function of the tidal phase, spatial separation between two consecutive internal solitary waves of a wave train, and minimum and maximum NRCS associated with an internal solitary wave may be used to infer characteristics of the interior ocean dynamics. These characteristics are, among others, depth and strength of the pycnocline and amplitudes of internal solitary waves. However, the possibility of inferring these characteristics is limited by different factors; among those are, for example, the complexity of the internal wave dynamics itself (effects of high nonlinearity and Coriolis force, multimodal behavior), the complexity of the environmental conditions influencing the internal wave dynamics (variable bathymetric features, largerscale current field, wind-induced currents), the complexity of the surface wave dynamics (surface wave breaking, effects of surfactants), the complexity of the wind field (local variability induced by the presence of coastal orography, atmospheric fronts, and other small-scale atmospheric features), and the 
complexity of the radar imaging of the sea surface (Bragg scattering versus specular reflection). Being aware of such complexity, in this paper we discuss the possibility of inferring characteristics of the interior ocean dynamics from the recognition and interpretation of sea surface patterns as well as from the analysis of the modulation of the NRCS associated with internal solitary waves by considering the case of the tidally induced internal dynamics in the Strait of Messina. In this oceanic region, owing to the interaction of strong semidiurnal tidal currents with the bottom topography, trains of northward as well as southward propagating internal solitary waves are generated, which have been often detected in synthetic aperture radar (SAR) images [Alpers and Salusti, 1983; Griffa et al., 1986; Di Sarra et al., 1987; Sapia and Salusti, 1987; Artale et al., 1990; Nicolò and Salusti, 1991; Brandt et al., 1997]. Our discussion will be based on the analysis of SAR images acquired during 160 overflights of the European Remote Sensing satellites (ERS-1/2) over the Strait of Messina carried out by Brandt et al. [1999]. The results of this analysis will be interpreted taking into account successive in situ measurements, partly described by Brandt et al. [1999], and results of numerical simulations carried out using a radar imaging model which assumes that wave-current interaction is the dominant mechanism for the modulation of the surface wave spectra over internal solitary waves.

\section{Available Data}

In the following we present an analysis of different SAR and in situ measurements referring to the tidally induced internal dynamics in the Strait of Messina which were carried out from 1991 to 1997 . The first set of data consists of ERS$1 / 2$ SAR images acquired during 160 satellite overflights over the sea area north and south of the sill in the Strait of Messina [Brandt et al., 1997].' The second set of data consists of highresolution hydrographic and current data acquired north and south of the strait sill during the Atlantic Ionian Stream '95 cruise (AIS '95) from aboard the NATO R/V Alliance of the SACLANT Undersea Research Centre (SACLANTCEN), La Spezia, Italy [Brandt et al., 1997]. The hydrographic data were obtained by using a conventional conductivity, temperature, depth (CTD) probe and a towed CTD chain, the current data by a vessel mounted acoustic Doppler current profiler (ADCP). The third set of data consists of simultaneously acquired in situ and ERS-2 SAR data. The in situ data (CTD and ADCP) collected during the Rapid Response '97 cruise (RR '97) were again obtained from aboard the NATO R/V Alliance.

\section{Recognition and Interpretation of Sea Surface Patterns of Internal Solitary Waves}

Brandt et al. [1997] studied the tidally induced internal dynamics in the Strait of Messina by using 160 ERS-1/2 SAR scenes acquired over the area of the Strait of Messina during 1991-1995. As a result of an analysis based on the recognition and interpretation of sea surface manifestations of internal solitary waves visible on these scenes, several characteristics of the tidally induced internal dynamics in the Strait of Messina emerge. Sea surface patterns of internal solitary waves are more frequent during periods where a strong nearsurface thermocline is known to be present, i.e., during summer, than during periods where this thermocline is known to be weak or absent. Furthermore, sea surface patterns of southward propagating internal solitary waves can be delineated on ERS-1/2 SAR images more frequently than patterns of northward propagating ones. In general, radar signatures associated with southward propagating internal solitary waves are stronger than radar signatures associated with northward propagating ones. The north-south asymmetry in the occurrence and strength of internal solitary waves in the Strait of Messina can be attributed to the north-south asymmetry in the strait bathymetry and in the horizontal density field [Brandt et $a l ., 1997,1999]$. In general, the spatial separation between the first two internal solitary waves of southward propagating wave trains is smaller in the period from July to September than in the period from October to June. This seasonal variability in the internal wave field is a consequence of the seasonal variability in the vertical density stratification in the Strait of Messina: Owing to a smaller depth of the pycnocline in the period from July to September than in the period from October to June, trains of internal solitary waves are generated with a smaller spatial separation between the first two waves. North of the strait sill, however, it is not possible to evidence clearly this seasonal variability. Trains of northward propagating internal solitary waves could be in fact detected in the SAR images only during spring (April-June) and summer (July-September), their individual variability in the spatial separation between the first two waves masking a possible seasonal variability in this parameter. Moreover, the individual variability of trains of northward propagating internal solitary waves manifests itself also in that sometimes they are associated with strong surface signatures with small wave front curvatures which propagate along the Calabrian coast in the direction of the strait axis, sometimes they are associated with less coherent, weak surface signatures with strong wave front curvatures which propagate almost circularly from the northern mouth of the Strait of Messina into the Tyrrhenian Sea. As the analysis of the data collected during AIS '95 suggests, such variability can be, at least partially, ascribed to a variability in the horizontal density gradient along the Strait of Messina connected with fluctuations of the large-scale, subbasin circulation of the central Mediterranean Sea. These fluctuations can result in a reversal of the climatological horizontal density gradient in the near surface layer along the Strait of Messina. As a consequence, very strong northward propagating internal solitary waves can be generated. These highly nonlinear waves are, however, vulnerable to wave instabilities, which can result in internal wave breaking causing a wave energy dissipation and a decrease in the wave train coherence.

\section{Analysis of the Modulation of the NRCS Associated With Internal Solitary Waves}

\subsection{In Situ and Remote Sensing Measurements}

On August 21 and 22, 1997, as a part of RR '97, in situ measurements were carried out in the area of the Strait of Messina from the NATO R/V Alliance of the SACLANTCEN. On August 22, 1997, the SAR image depicted in Figure 1 was acquired by ERS- 2 . At the same time, the density and velocity structure of the leading internal solitary wave of a southward propagating wave train was observed with the towed CTD chain and the vessel mounted ADCP by passing it at a ship speed of about $2.5 \mathrm{~m} / \mathrm{s}$. In Figure 1 the ship position 


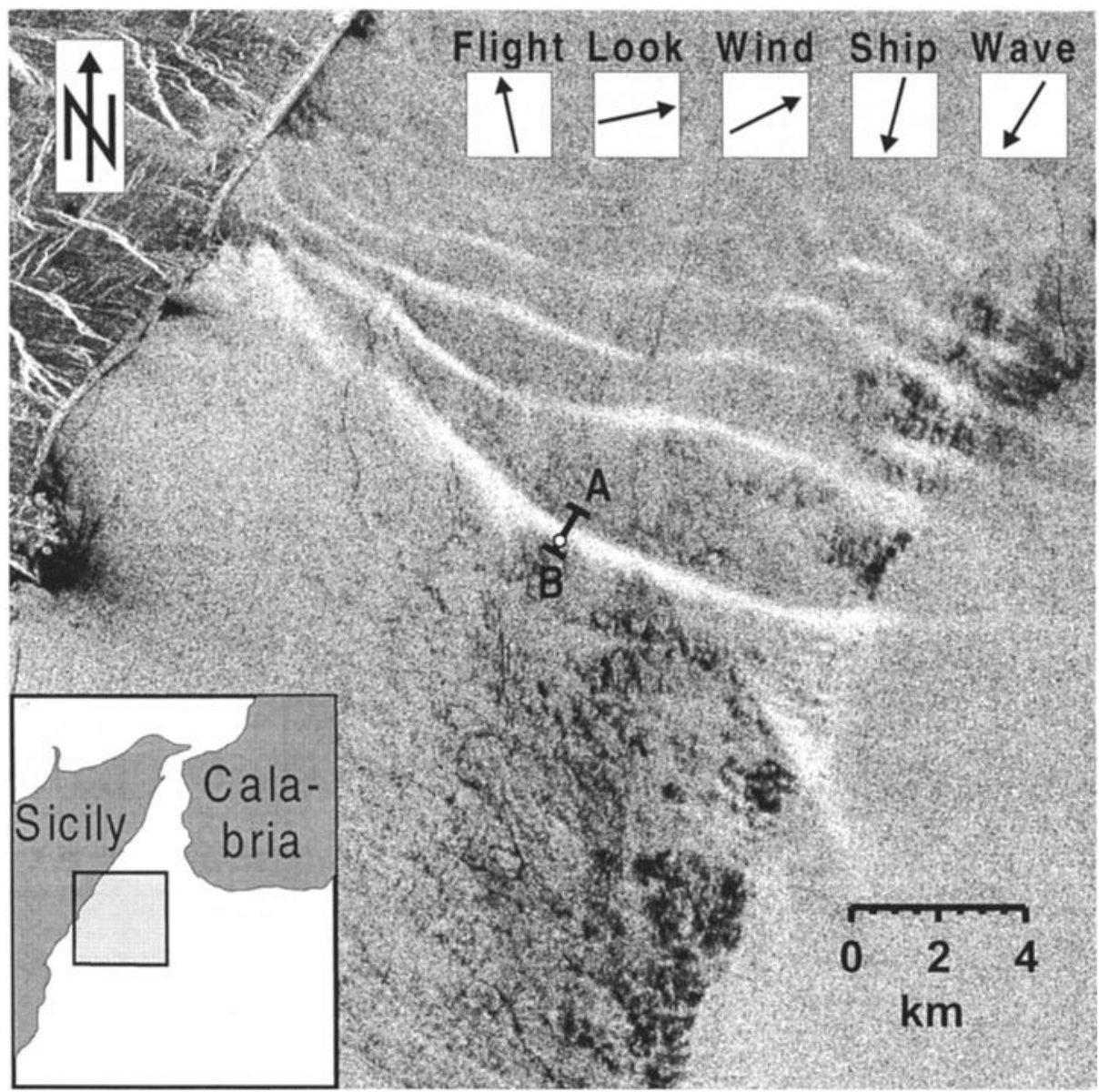

Figure 1. ERS-2 SAR image of a region south of the Strait of Messina (see inserted geographical map) acquired at 2113 UTC August 22, 1997. The image shows sea surface patterns of southward propagating internal solitary waves. The SAR operates at a radar frequency of $5.3 \mathrm{GHz}$ and VV polarization and illuminates the sea surface at a mean incidence angle of $23^{\circ}$. The line AB indicates the location of the NRCS profile considered in this work; the white dot on the line AB denotes the position of NATO R/V Alliance at the time of the SAR measurement. The arrows given in the upper right part of the figure represent satellite flight direction, radar look direction, wind direction at the ship position, ship heading, and internal wave propagation direction near the ship position.

at the time of the SAR measurements is indicated. At this time the ship heading was $194^{\circ}$ from north, whereas the propagation direction of the internal wave near the ship was $211^{\circ}$ from north, as estimated from the SAR image. From several passes of the ship through the leading wave, its propagation speed $c$ could be estimated as $1.2 \mathrm{~m} / \mathrm{s}$. Given this propagation speed and the angle formed by ship heading and wave propagation direction, the measured density and velocity fields could be referred to the time of the ERS-2 SAR data acquisition and to the vertical section at the ship position perpendicular to the wave crest. Figure 2 shows the transformed density field together with the corresponding velocity vectors composed of the vertical velocity component and the horizontal velocity component in wave propagation direction. The crest-to-trough amplitude of the measured solitary wave is about $30 \mathrm{~m}$. The maximum horizontal current velocity (more than $0.8 \mathrm{~m} / \mathrm{s}$ ) is found near the sea surface.

\subsection{Radar Imaging Model}

The University of Hamburg has developed an advanced radar imaging model for the simulation of synthetic aperture ra- dar signatures of oceanic and atmospheric features over the ocean [Romeiser et al., 1994, 1997]. The model accounts for contributions of the full ocean wave spectrum to the radar backscatter from the ocean surface. It is based on resonant Bragg scattering theory in a composite surface model expansion, following the theoretical expressions given by Valenzuela [1978]. The proposed model is similar to the one presented by Lyzenga and Bennett [1988], but it includes additional terms like, for example, hydrodynamic long wave-short wave interaction terms accounting for the asymmetric distribution of scatterers along intermediate-scale surface waves and the resulting upwind/downwind difference of the backscattered signal. Using a slightly optimized parameterization of the ocean wave spectrum, the model was shown to reproduce measured absolute NRCS values for wide ranges of wind speeds, radar frequencies, look directions, and for horizontal $(\mathrm{HH})$ and vertical (VV) polarization quite well [Romeiser et al., 1997].

A general underestimation of radar signatures of hydrodynamic features like spatially varying surface currents over underwater bottom topography in tidal waters and oceanic internal waves, in particular at high radar frequency bands ( $\mathrm{C}$ band 


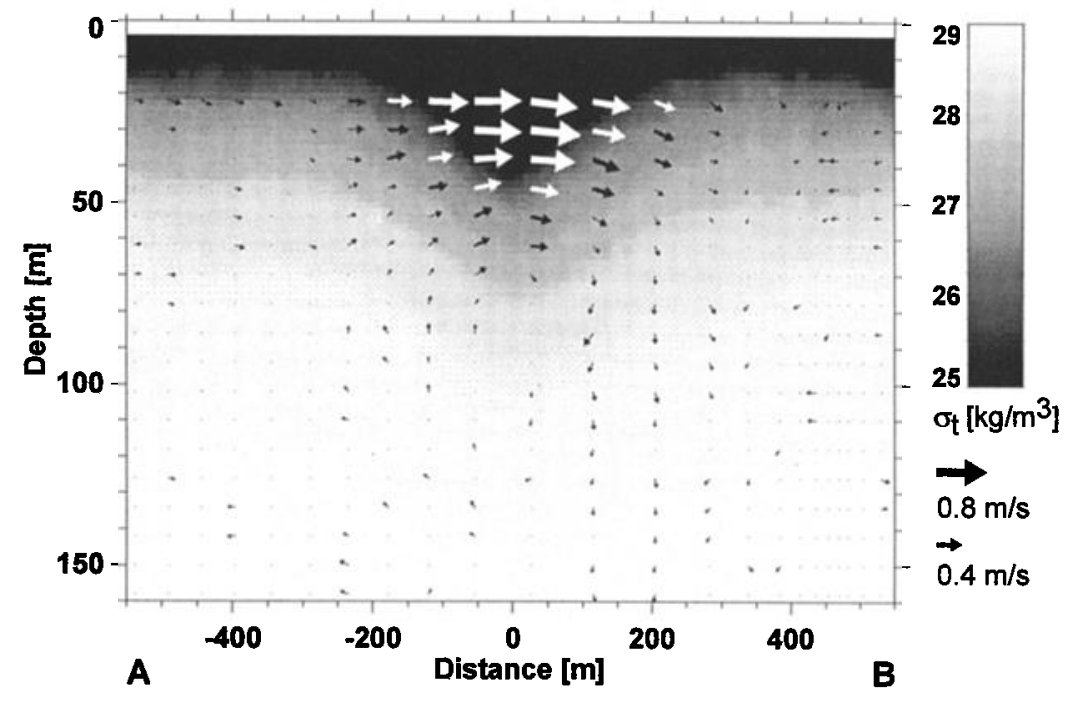

Figure 2. Measured density and velocity field. Both fields refer to the time of the SAR measurements (see Figure 1), their horizontal distribution to the line $\mathrm{AB}$ of Figure 1. The coordinate transformation is performed by using a propagation speed of the internal solitary wave of $1.2 \mathrm{~m} / \mathrm{s}$. The velocity vectors are calculated by using the vertical velocity component and the horizontal velocity component in the wave propagation direction.

and higher), is a well-known problem of contemporary radar imaging models [Romeiser and Alpers, 1997]. It is believed to result mainly from simplifications in the wave-current interaction models which are used for the calculation of spatially varying wave spectra. Lyzenga [1996, 1998] has shown that model results can be clearly improved by the inclusion of the effects of wave breaking and second-order hydrodynamic modulation of short ripple waves by intermediate-scale waves. In our opinion, also spatial variations of the wind stress in correlation with surface roughness variations can affect the intensity variations of short waves considerably. However, none of these effects is included in the version of our model that has been used for the simulation runs presented in the following. In order to obtain realistic modulation depths, we have instead reduced the relaxation rate of waves, a parameter that determines the strength of the hydrodynamic modulation according to weak hydrodynamic interaction theory [Alpers and Hennings, 1984], by a factor 8 in all simulations. In view of the fact that this is practically equivalent to an increase of the wave modulation by other means, that the relaxation rate is generally not known very well (existing paramaterizations given by different authors vary by up to an order of magnitude, see Caponi et al. [1988]), and that we intend to depict general trends in this paper rather than discussing details like the dependence of the shape of radar signatures on wind speed or other parameters, this approach appears to be justified. On the basis of the proposed radar imaging model and the above-mentioned modification of the relaxation rate, we shall discuss in the following the sensitivity of radar signatures of oceanic internal waves to changes in the surface wind field and in parameters of the interior ocean.

\subsection{Numerical Simulations}

Figure 3a shows near-surface velocity fields referring to the observed internal solitary wave discussed in section 4.1. In this figure, the diamonds represent near-surface velocity data measured with the ADCP in a depth range from 18 to $26 \mathrm{~m}$, the solid line is obtained by fitting to these data a $\operatorname{sech}^{2}$ profile, and the dotted line is a solution of the two-layer Korteweg-de Vries (KdV) equation that will be discussed later. Figure $3 \mathrm{~b}$ shows NRCS profiles also referring to the observed internal solitary wave discussed in section 4.1. The solid line represents the NRCS measured by the ERS-2 SAR, the dashed line the corresponding NRCS resulting from our numerical simulations. The simulations were performed by in-
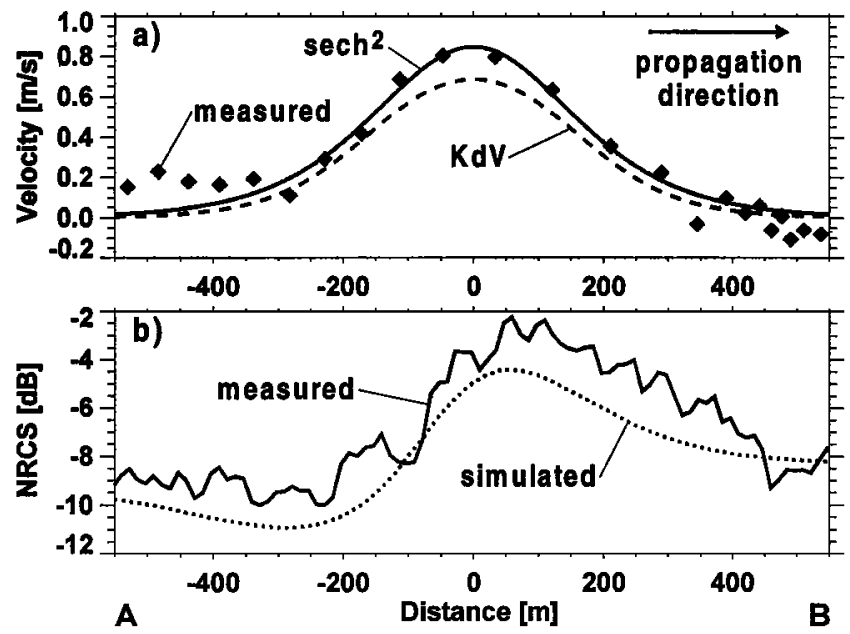

Figure 3. Horizontal distribution of (a) the horizontal nearsurface current velocity in wave propagation direction and (b) the corresponding NRCS referring to the observed internal solitary wave discussed in section 4.1. In Figure 3a, the diamonds represent near-surface velocity data measured with the ADCP in a depth range from 18 to $26 \mathrm{~m}$; the solid line is obtained by fitting to these data a sech ${ }^{2}$ profile, and the dotted line is a solution of the two-layer KdV equation. In Figure $3 b$, the solid line represents the NRCS measured by the SAR (averaged over 48 pixels $(600 \mathrm{~m})$ perpendicular to the line $A B$ in Figure 1) and the dotted line the corresponding NRCS resulting from our numerical simulations. 
serting the $\operatorname{sech}^{2}$ fitting shown in Figure $3 a$ into the radar imaging model. This curve was chosen in order to eliminate small-scale variations present in the observed velocity data. The wind speed and direction used in the numerical simulations are those observed at the time of the SAR measurements. Their values are $2.2 \mathrm{~m} / \mathrm{s}$ and $148^{\circ}$, respectively. The radar look direction is $133^{\circ}$. Note that these directions, as well as all directions given in the following, are measured counterclockwise starting from the direction of the wave propagation which was $211^{\circ}$ from north. Further parameters used in the numerical simulations are listed in the caption of Figure 1. A comparison between measured (Figure $3 \mathrm{~b}$, solid line) and simulated (Figure $3 b$, dotted line) NRCS shows that shapes and modulation depths agree quite well.

To elucidate the wind dependence of radar signatures associated with the internal solitary wave, we performed several numerical simulations with different wind directions and speeds. Figures $4 \mathrm{a}$ and $4 \mathrm{~b}$ show the simulated minimum and maximum NRCS, respectively, relative to the undisturbed NRCS, i.e., the negative and positive parts of the modulations, in the wind direction-wind speed space. Note that the undisturbed NRCS corresponds to the NRCS calculated by the model far from the region where the internal solitary wave is present. As expected, the modulation depths are greater for low wind speeds. The simulated NRCS shows a strong dependence on wind direction. While for winds blowing against the direction of internal wave propagation (around $180^{\circ}$ ) the radar signatures are dominated by a positive modulation, they are dominated by a negative modulation for winds blowing in the opposite direction (around $0^{\circ}$ ).
In order to analyze the dependence of the radar signatures associated with internal solitary waves on internal wave parameters and wind conditions, we have chosen as a theoretical model for the internal wave dynamics the two-layer $\mathrm{KdV}$ equation. Although it describes only weakly nonlinear and weakly dispersive internal waves in a two-layer ocean [Whitham, 1974], it has been shown that reasonably good agreement between model results and oceanic measurements of internal wave characteristics can often be obtained [see, e.g., Osborne and Burch, 1980; Artale et al., 1990]. The solitary wave solution of the two-layer $\mathrm{KdV}$ equation for the interface displacement $A(x, t)$ is given by

$$
A(x, t)=A_{0} \operatorname{sech}^{2}\left(\frac{1}{2} k(x-c t)\right)
$$

with $k^{2}=A_{0} \alpha /(3 \gamma), \alpha=-3\left(H_{2}-H_{1}\right) /\left(2 H_{1} H_{2}\right), \gamma=H_{1} H_{2} / 6, c=$ $c_{0}\left(1+\alpha A_{0} / 3\right)$, and $c_{0}{ }^{2}=(\Delta \rho / \rho) g H_{1} H_{2} /\left(H_{1}+H_{2}\right)$, where $A_{0}$ is the amplitude of the internal solitary wave, $H_{1}$ and $H_{2}$ are the undisturbed upper and lower layer thickness, respectively, $\Delta \rho / \rho$ is the relative density difference, $g=9.81 \mathrm{~m} / \mathrm{s}^{2}$ is the gravitational acceleration, $x$ is the horizontal spatial coordinate, and $t$ is time. The upper layer velocity is then given by

$$
u(x, t)=\frac{-c A(x, t)}{H_{1}-A(x, t)}
$$

By using $A_{0}=-32 \mathrm{~m}, H_{1}=24 \mathrm{~m}, H_{2}=976 \mathrm{~m}$, and $\Delta \rho / \rho=$ 0.0023 , which are estimated from the measurements, we obtain good agreement between the measured near-surface ve-

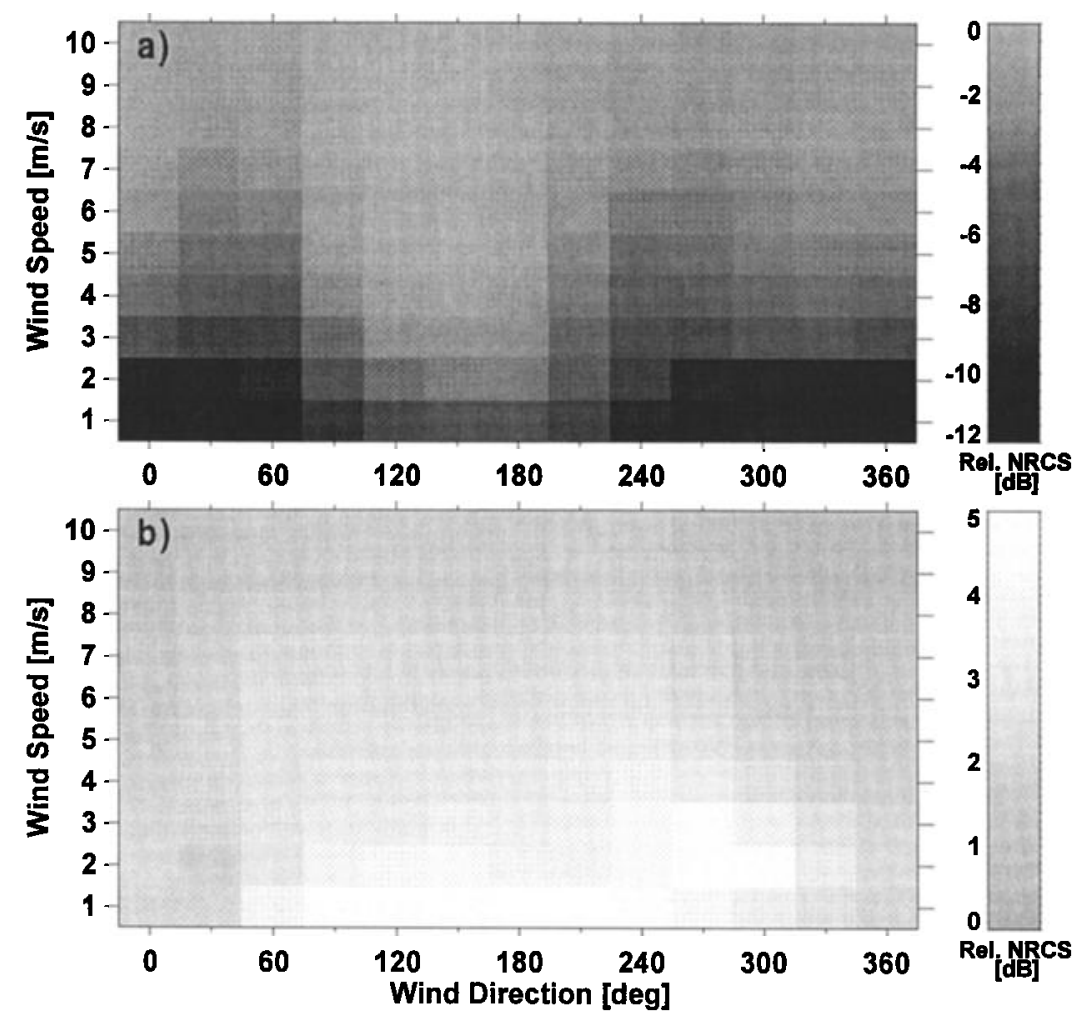

Figure 4. Simulated (a) minimum and (b) maximum NRCS relative to the undisturbed NRCS in the wind direction-wind speed space. The parameters used in the simulation are the same as in the simulation depicted in Figure $3 b$. 

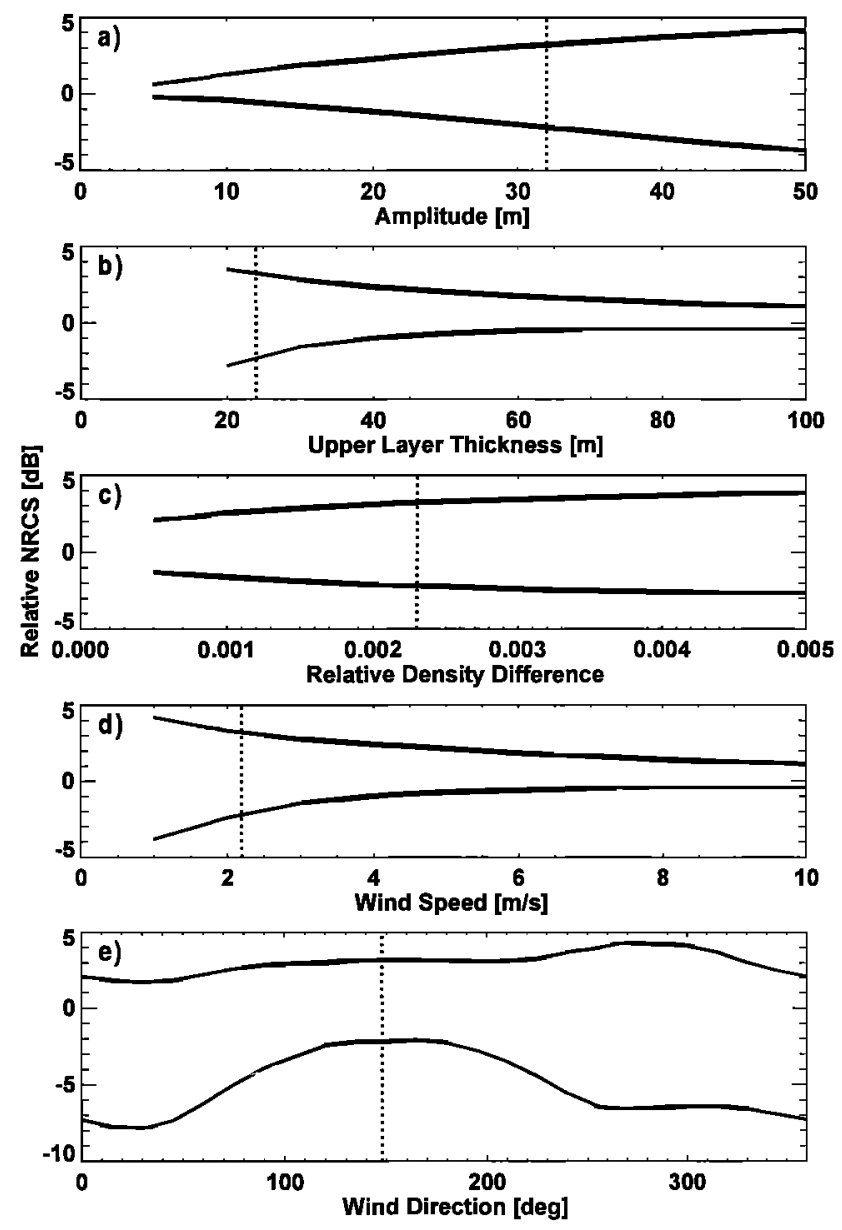

Figure 5. Simulated minimum and maximum NRCS relative to the undisturbed NRCS as functions of different $(\mathrm{a}-\mathrm{c})$ internal wave and (d-e) wind parameters. The dotted line in each panel gives the value of the parameter assumed to be constant in the simulations whose results are shown in the other panels. These values correspond to the values observed at the time of the SAR measurements.

locity (Figure 3a, diamonds) and the theoretical velocity of the two-layer KdV equation (Figure 3a, dashed line).

Figure 5 shows the simulated minimum and maximum NRCS relative to the undisturbed NRCS as functions of internal wave parameters in accordance with equation 1 (internal wave amplitude (Figure 5a), undisturbed upper layer thickness (Figure $5 b$ ), relative density difference (Figure $5 c$ )) and of wind conditions (wind speed (Figure 5d) and wind direction (Figure 5e)). The strength of the simulated radar signatures increases as the wave amplitude increases (Figure 5a), as the upper layer thickness decreases (Figure $5 b$ ), and as the relative density difference increases (Figure 5c). Note that the radar signal dependence on the relative density difference is weak. This results, among others, from the fact that in the internal wave model used in our simulations this parameter affects only the wave propagation speed but not the wave structure. A comparison between the curves referring to the internal wave parameters (Figures 5a-c) and those referring to the wind conditions (Figures 5d-e) shows that the dependence of the modulation depths of the NRCS associated with internal solitary waves on these parameters is of the same order.

\section{Conclusions}

In this paper we have shown that an accurate knowledge of wind parameters is crucial for extracting valuable information about the interior ocean dynamics from the modulation depth of measured NRCS associated with internal solitary waves. In particular the dependence of the modulation depth of the NRCS associated with internal solitary waves on internal wave parameters (internal wave amplitude, undisturbed upper layer thickness, and relative density difference) and on wind parameters (wind speed and direction) are of the same order. Our investigation yields that different directions of the wind blowing over an internal solitary wave can result in different radar signals, ranging from signals dominated by an increased radar backscatter (bright bands on SAR images) to signals dominated by a reduced radar backscatter (dark bands on SAR images). We have also shown that it is possible to extract valuable information about the interior ocean dynamics by the recognition and the interpretation of sea surface patterns of oceanic internal solitary waves. In particular the variability of sea surface patterns of internal solitary waves in the Strait of Messina reflects the variability in the horizontal and vertical density distribution in that area. The analysis of a large number of SAR images of an oceanic region where internal solitary waves exist, possibly in conjunction with an accurate knowledge of wind parameters, could thus add valuable information to the understanding of the long-term oceanic variability in that region.

Acknowledgments. We thank Jürgen Sellschopp for his help during the experimental phase of this work and Marcus Dengler for the processing of the ADCP data. This work was partly supported by the European Commission under contract no. MAS3-CT95-0027 (MORSE) and by the European Space Agency under contract no. $11969 / 96 / \mathrm{NL} / \mathrm{CN}$.

\section{References}

Alpers, W., Theory of radar imaging of internal waves, Nature, 314 , 245-247, 1985

Alpers, W., and I. Hennings, A theory of the imaging mechanism of underwater bottom topography by real and synthetic aperture radar, J. Geophys. Res., 89, 10,529-10,546, 1984.

Alpers, W., and E. Salusti, Scylla and Charybdis observed from space, J. Geophys. Res., 88, 1800-1808, 1983.

Alpers, W., P. Brandt, A. Rubino, and J. O. Backhaus, Recent contributions of remote sensing to the study of internal waves in the straits of Gibraltar and Messina, in Dynamics of Mediterranean Straits and Channels, CIESM Sci. Ser. 2, Bulletin de l'Institut Océanographique, Monaco, vol. 17, edited by F. Briand, pp. 2140, Institut Océanographique, Monaco, 1996.

Apel, J. R., and F. I. Gonzales, Nonlinear features of internal waves off Baja California as observed from the SEASAT imaging radar, J. Geophys. Res., 88, 4459-4466, 1983.

Apel, J. R., H. M. Bryne, J. R. Proni, and R. L. Charnell, Observations of oceanic internal waves from the Earth Resources Technology Satellite, J. Geophys. Res., 80, 865-881, 1975.

Apel, J. R., R. F. Gasparovic, D. R. Thompson, and B. L. Gotwols, Signatures of surface wave/internal wave interactions: Experiment and theory, Dyn. Atmos. Oceans, 12, 89-106, Elsevier, Amsterdam, 1988.

Apel, J. R., L. A. Ostrovsky, and Y. A. Stepanyants, Internal solitons in the ocean, Tech. Rep. MERCJRA0695, $70 \mathrm{pp}$., Milton S. Eisenhower Res. Cent., Appl. Phys. Lab., Johns Hopkins Univ., 1995.

Artale, V., D. Levi, S. Marullo, and R. Santolieri, Analysis of nonlinear internal waves observed by Landsat thematic mapper, J. Geophys. Res., 95, 16,065-16,073, 1990.

Brandt, P., A. Rubino, W. Alpers, and J. O. Backhaus, Internal waves in the Strait of Messina studied by a numerical model and syn- 
thetic aperture radar images from the ERS $1 / 2$ satellites, $J$. Phys. Oceanogr., 27, 648-663, 1997.

Brandt, P., A. Rubino, D. Quadfasel, W. Alpers, J. Sellschopp, and H.-V. Fiekas, Evidence for the influence of Atlantic-Ionian stream fluctuations on the tidally induced internal dynamics in the Strait of Messina, J. Phys. Oceanogr., 29, 1071-1080, 1999.

Caponi, E. A., D. R. Crawford, H. C. Yuen, and P. G. Saffman, Modulation of radar backscatter from the ocean by a variable surface current, J. Geophys. Res., 93, 12,249-12,263, 1988.

da Silva, J. C. B., S. A. Ermakov, I. S. Robinson, D. R. G. Jeans, and S. V. Kijashko, Role of surface films in ERS SAR signatures of internal waves on the shelf, 1, Short-period internal waves, $J$. Geophys. Res., 103, 8009-8031, 1998.

Di Sarra, A., A. Pace, and E. Salusti, Long internal waves and columnar disturbances in the Strait of Messina, J. Geophys. Res., 92, 6495-6500, 1987

Ermakov, S. A., J. C. B. da Silva, and I. S. Robinson, Role of surface films in ERS SAR signatures of internal waves on the shelf, 2, Internal tidal waves, J. Geophys. Res., 103, 8033-8043, 1998.

Griffa, A., S. Marullo, R. Santolieri, and A. Viola, Preliminary observations of large-amplitude tidal internal waves near the Strait of Messina, Cont. Shelf Res., 6, 677-687, 1986.

Lyzenga, D. R., Effects of wave breaking on SAR signatures observed near the edge of the Gulf Stream, in Proc. 1996 International Geoscience and Remote Sensing Symposium (IGARSS '96), pp. 908-910, Inst. of Elec. and Electron. Eng., Piscataway, N.J., 1996.

Lyzenga, D. R., Effects of intermediate-scale waves on radar signatures of ocean fronts and internal waves, J. Geophys. Res., 103, $18,759-18,768,1998$

Lyzenga, D. R., and J. R. Bennett, Full-spectrum modeling of synthetic aperture radar internal wave signatures, J. Geophys. Res., $93,12,345-12,354,1988$.

Nicold, L., and E. Salusti, Field and satellite observations of large amplitude internal tidal wave trains south of the Strait of Messina, Mediterranean Sea, Ann. Geophys., 9, 534-539, 1991.

Osborne, A. R., and T. L. Burch, Internal solitons in the Andaman Sea, Science, 208, 451-460, 1980.

Richez, C., Airborne synthetic aperture radar trackıng of internal waves in the Strait of Gibraltar, Prog. Oceanogr., 33, 93-159, 1994.

Rodenas, J. A., and R. Garello, Wavelet analysis in SAR ocean image profiles for internal wave detection and wavelength estimation, IEEE Trans. Geosci. Remote Sens., 35, 933-945, 1997.

Romeiser, R., and W. Alpers, An improved composite surface model for the radar backscattering cross section of the ocean surface, 2 , Model response to surface roughness variations and radar imaging of underwater bottom topography, J. Geophys. Res., 102, 25,25125,267, 1997

Romeiser, R., A. Schmidt, and W. Alpers, A three-scale composite surface model for the ocean wave-radar modulation transfer function, J. Geophys. Res., 99, 9785-9801, 1994.

Romeiser, R., W. Alpers, and V. Wismann, An improved composite surface model for the radar backscattering cross section of the ocean surface, 1 , Theory of the model and optimization/validation by scatterometer data, J. Geophys. Res., 102, 25,237-25,250, 1997.

Sapia, A., and E. Salusti, Observation of nonlinear internal solitary wave trains at the northern and southern mouths of the Strait of Messina, Deep Sea Res., 34, 1081-1092, 1987.

Valenzuela, G. R., Theories for the interaction of electromagnetic and ocean waves - A review, Boundary Layer Meteorol., 13, 61-85, 1978.

Watson, G., and I. S. Robinson, A study of internal wave propagation in the Strait of Gibraltar using shore-based marine radar images, J. Phys Oceanogr., 20, 374-395, 1990.

Whitham, G. B., Linear and Nonlinear Waves, 636 pp., John Wiley, New York, 1974.

P. Brandt, Institut für Meereskunde, Universität Kiel, Düsternbrooker Weg 20, 24105 Kiel, Germany. (pbrandt@ifm.uni-kiel.de)

R. Romeiser and A. Rubino, Institut für Meereskunde, Universität

Hamburg, Troplowitzstraße 7, 22529 Hamburg, Germany. (romeiser @ifm.uni-hamburg.de; rubino@ifm.uni-hamburg.de)

(Received August 6, 1998; revised March 19, 1999; accepted March 26, 1999) 